\title{
NCR PEPTIDES - PLANT EFFECTORS GOVERNING TERMINAL DIFFERENTIATION OF NODULE BACTERIA INTO THE SYMBIOTIC FORM
}

(review)

\section{M.S. KLIUKOVA', V.A. ZHUKOV1, I.A. TIKHONOVICH'1, 2}

\author{
${ }^{1}$ All-Russian Research Institute for Agricultural Microbiology, Federal Agency of Scientific Organizations, 3, sh. Podbel'skogo, \\ St. Petersburg, 196608 Russia, e-mail: zhukoff01@yahoo.com, Zhukov@ARRIAM.ru (corresponding author); \\ ${ }^{2}$ Saint-Petersburg State University, 7/9, Universitetskaya nab., St. Petersburg, 199034 Russia \\ ORCID: \\ Kliukova M.S. orcid.org/0000-0003-1119-5512 \\ Tikhonovich I.A. orcid.org/0000-0001-8968-854X \\ Zhukov V.A. orcid.org/0000-0002-2411-9191 \\ The authors declare no conflict of interests \\ Acknowledgements: \\ Supported by Russian Science Foundation (grant № 14-24-00135); V.A. Zhukov is supported by grant № 14-04- \\ 01442-a form Russian Foundation for Basic Research \\ Received December 12, 2016
}

\section{Abstract}

Uptake of mineral nutrients from the soil is the challenge of plant survival. In particular, the availability of such macro-elements as nitrogen and phosphorus is the limiting factor for plant growth and development. Some plant genera overcome this limitation by establishing symbiotic relationships with microorganisms. A remarkable example of such symbiosis is one between legumes and rhizobia - a group of nitrogen fixing soil bacteria. Rhizobial penetration into roots of a specific host plant causes initiation of a specialized organ, symbiotic nodule. Within cells of symbiotic nodule free-living bacteria differentiate into a symbiotic form called «bacteroids». Such organelle-like structures provide plants with fixed nitrogen in exchange for nutrients (B.J. Ferguson et al., 2010). A number of legumes form nodules, in which bacteria terminally (irreversibly) differentiate into bacteroids, thus losing the opportunity to return to the free-living state. Terminal differentiation of bacteroids begins soon after release of the rhizobia into plant cells and leads to morphological, physiological and genetic changes in bacterial cells. It has been shown that a large family of antimicrobial peptides of plants called Nodule-specific Cysteine-Rich peptides (NCR peptides) plays a key regulatory role in this process (P. Mergaert et al., 2003). Its representatives are similar in structure and mode of action to defensins - plant innate immunity factors; however, NCR genes are expressed only in nodules, which fact is reflected in their name. At the moment, about 700 genes encoding NCR peptides that are highly variable in their amino acid sequence but possess a distinct conservative cysteine motif required for the adoption of correct conformation were identified in the genome of the model legume Medicago truncatula Gaertn. NCR peptides are delivered to their intracellular target symbiosome (cell compartments containing bacteroides) triggering the process of differentiation by interacting with the components of membranes and various intracellular targets of bacteria (D. Wang et al., 2010). The most studied member of this family in M. truncatula is MtNCR247 a cationic peptide with four cysteines forming two disulfide bonds in oxidized form. MtNCR247 affects transcription, translation and cell division processes in M. truncatula microsymbiont Sinorhizobium meliloti at low concentrations, and also exhibits antimicrobial activity at higher concentrations (A. Farkas et al., 2014). To date, NCR peptides are identified only in plants belonging to IRLC (Inverted Repeatlacking Clade) legumes which are characterized by terminal differentiation of bacteria into bacteroids. Probably, evolutionary acquisition of the variable gene family encoding NCR peptides has been the selective advantage of this group of plants.

Keywords: rhizobium-legume symbiosis, nitrogen-fixing nodules, differentiation of bacteroides, NCR-peptides, regulation of symbiosis development

The legume family (Fabaceae) includes primary food and feed species of cultivated plants such as peas, soybeans, clover, chickpeas and lucerne. It is the third largest group of angiosperms and the second one of food and feed crops grown worldwide [1]. The important environmental advantage of legumes is the 
opportunity to grow with virtually no fixed nitrogen in the soil through fixation of atmospheric nitrogen by symbiotic nodule bacteria [2, 3].

When establishing nitrogen-fixing symbiosis, rhizobia selectively penetrate into roots of legumes, which leads to the development of special root structures called nodules [4]. The ontogeny of nodules is a well-organized process based on the coordinated expression of specialized plant and bacterial genes [5[. A large part of a complex system of genes in plants that control the nodule development is needed to control microsymbiont by a host plant.

Inside the nodule, the bacteria differentiate into bacteroids and carry out symbiotic nitrogen fixation, i.e. reduction of molecular nitrogen to ammonium ion using the enzymic complex of nitrogenase [6, 7]. In the legume nodules belonging to the IRLC (Inverted Repeat-lacking Clade) group, the transformation of rhizobia into bacteroids is irreversible (terminal differentiation); in other plants, it is a reversible process [8-10]. If the rhizobia strain is capable of nodulation on the roots of a wide range of plants, the degree of bacteria differentiation into bacteroids and its reversibility strictly corresponds to species of a host plant, from which it follows that the differentiation process is induced through plant signals [11-13].

In Medicago truncatula model legume, as such factors there may be at least 800 nodule-specific symbiotic peptides, the majority of which (over 700) belong to the group of nodule-specific cysteine-rich (NCR) peptides [14-17]. NCR peptides have been also described for other legumes belonging to the same IRLC clade, i.e. beans (Vicia faba) [18], white clover (Trifolium repens) [19], Eastern galega (Galega orientalis) [20], and English peas (Pisum sativum L.) [21-23]. NCR peptides have been identified in experiments on identification of nodule-specific protein molecules (nodulins) [21], but not all nodulins refer to NCR peptides.

The aim of the present article is generalization and structuring of information accumulated over the last decade, in relation to the regulation of symbiotic bacteria differentiation in establishing nitrogen-fixing symbiosis. For the first time, a complete characterization of the numerous protein NCR peptides family has been given. The issues of their structure, functions, targets, modes of action and its intended path of evolution have been also discussed in detail.

The genes of NCR peptides belong to the extensive group of defensinlike genes, various representatives of which are found in the genomes of vertebrates (encode proteins involved in the acquired immunity), invertebrates (e.g., encode a component of the scorpion toxin) and plants [14, 24, 25]. In turn, defensins are a group of antimicrobial peptides (AMP), which are produced by almost all living organisms and play a key role in the innate immunity [26-28]. The general mode of action of antimicrobial peptides is the disruption of microbial membranes and (or) inducing the formation of pores, which leads to lysis of bacterial cells and also makes possible the interaction of peptides with intracellular targets (DNA, RNA and various proteins) [29-31].

NCR peptides, along with plant defensins, by amino acid composition belong to a vast family of cysteine cluster proteins (CCPs) containing a conservative cysteine cluster of $4,6,8$ or 10 cysteine residues in conservative positions [32-34]. Nodule-specific CCPs, that is, NCR peptides, represent one of $10 \mathrm{CCP}$ subgroups $[34,35]$. Like the genes of defensins, the genes of NCR peptides encode short (30-60 amino acid residues) secretable polypeptides with a high variability in amino-acid sequence, which determines their specificity and different mechanisms of action [14, 36, 37]. Unlike defensins, the key function of which is involvement in protective processes and a negative impact on bacteria, NCR peptides play a positive regulatory role in the nodules of legumes controlling the rhizobia differentiation into nitrogen-fixing bacteroids [11, 38, 39]. The antimicrobial activity 
of NCR peptides is reflected in the fact that the differentiation into bacteroids under their action is irreversible. Furthermore, the bacteria lose their ability to reproduce.

The expression of the genes encoding NCR peptides is specific to the nodules. However, certain groups of genes are activated together, resulting in several successive "waves" of their expression at different stages of nodule development [40]. Just synthesized NCR peptides contain an N-terminal signal sequence that defines their transport to the endoplasmic reticulum [11, 14]. In the transport of NCR peptides, the key role is played by signal peptidase cutting off the signal sequence from the mature peptide in sorting proteins on the endoplasmic reticulum [41]. In $M$. truncatula mutants of MtDNF1 gene encoding a nodule-specific signal peptidase subunit, NCR peptides retain the signal sequences and accumulate in the endoplasmic reticulum, without getting into symbiosomes resulting in the absence of bacteroids differentiation [11, 16, 41]. In the case of the normal development of symbiosis, with the gene expression different sets of NCR peptides are delivered to the endosymbiont and mediate the subsequent events of its differentiation [16].

For some NCR peptides (e.g., MtNCR247 and MtNCR335), an ability to interact with the membrane of bacterial cells has been shown, which in vitro leads to the loss of both rhizobia and human pathogens and plants [11, 42]. However, in vivo (in the nodule cells) symbiotic peptides do not violate the permeability of the bacterial membrane so much that it should lead to cell lysis [31]. Probably, the increase in the permeability of the membrane promotes the penetration of NCR peptides into the bacterial cells.

Of bacteroids present in the cells of $M$. truncatula nodules, about 140 different NCR peptides can be identified, which indicates the possibility of their penetration into the bacterial cell, as well as their high stability and potential interaction with intracellular targets [43]. One of MtNCR247 targets is bacterial protein FtsZ, which plays an important role in the formation of the cell wall in the cell division [44-46]. Another partner of MtNCR247 is chaperone GroEL, which is required for full activation of nodulation genes and assembly of nitrogenase complex [47]. Also, MtNCR247 exposure changes the expression of some regulatory genes critical to the cell cycle progression $(\operatorname{ctr} A, \operatorname{gcr} A, \operatorname{dnaA})$, which might be related to stopping the proliferation of bacteria in the plant cells [45].

Rhizobia have protective mechanisms to withstand the effects of vegetable NCR peptides [48]. In particular, some protection against NCR peptides is provided by the $B a c A$ gene encoding the protein of the family of ABC transporters [49-51]. Thus, $S$. meliloti mutant of the bacA gene shows hypersensitivity toward MtNCR247 in vitro and in vivo (bacteria are degraded soon after release of the lucerne nodule into cells, while bacterial strains of the wild type remain viable and are differentiated into bacteroids) [52-54]. In addition, the metallopeptidase gene $H r r P$ (host range restriction peptidase), encoding enzyme capable to cut NCR peptides, has been described [55, 56]. Some Bradyrhizobium strains for a successful nitrogen-fixing symbiosis require the presence of styrole-like lipids (hopanoids) in the membrane, probably, enhancing its strength and providing protection against NCR peptides [57, 58].

An important feature of the gene family of NCR peptides is their clustered organization within the genome. The Clusters of genes, which encode NCR peptides, are evenly distributed on eight chromosomes in $M$. truncatula and, apparently, originated from the repeated duplication and subsequent diversification of sequences [9]. Since the promoter regions of genes encoding NCR peptides are also similar, their expression is highly consistent. Sequencing RNA samples from the nodule zones, carved out of the preparation by laser micro-dissection, 
showed that the genes of NCR peptides can be divided into several groups based on their spatial-temporal expression profile [16]. Obviously, the expression of certain groups of NCR peptides genes is needed only at the specific stage of nodule development [40].

Scheme of the proposed evolution of NCR peptides genes of Medicago truncatula and Pisum sativum. Genes of NCR peptides originated about 25 million years ago in the common ancestor of the IRLC (Inverted Repeat-lacking Clade) group. Subsequently, the duplication, diversification and emergence of a large number of genes encoding antimicrobial peptides with low sequence conservation, which became the basis of the diversity of their activity and physiological functions. Some of NCR peptides gained unique functions distinguishing them from the main group and essential for successful symbiosis; part of the sequences was becoming pseudogenes and was losing a biological function. The color indicates the degree of differences in the variability of the nucleotide sequences of NCR peptides genes and their changes in the evolution (mutation and recombination). $\mathrm{X}$ means that the gene, which encoded NCR-peptide, due to mutation evolved in pseudogene and lost its original function.

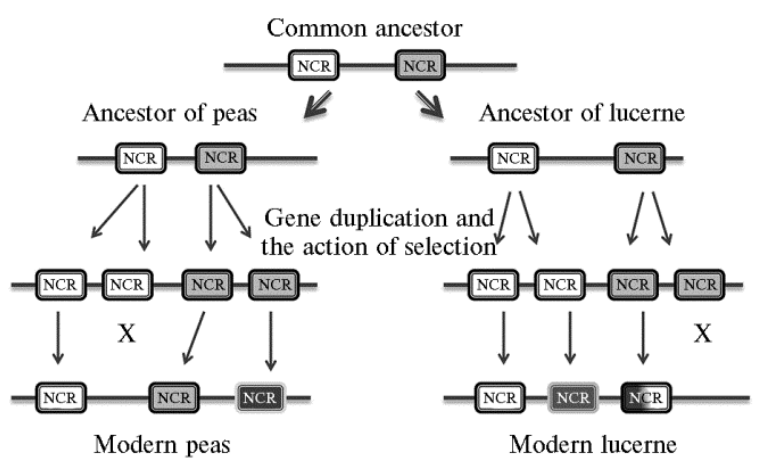
selection in favor of the highest functionality led to the

Despite the previously described interchangeability of antimicrobial molecules [14], there is data on the unique properties and functions of NCR peptides, the absence of which interrupts establishment of nitrogen-fixing symbiosis. Thus, MtNCR211, toxic to $S$. meliloti in vitro, is necessary for the survival of bacteroids in planta, because mutation in its gene leads to the death of bacteroids in the nodule cells [60]. Similarly, to maintain bacteroids, MtNCR169 is necessary, in the absence of which their differentiation practically does not take place and, as a result, nitrogen is not fixed [61]. These two NCR peptides are characterized by similar localization in planta $[60,61]$. M. truncatula mutants of the MtDNF4 (=MtNCR211) and MtDNF7 (=MtNCR169) genes have similar transcriptomic profiles [62]. Despite this, the role of each of these peptides is unique, because in the mutant by the MtNCR211 gene, lysis of bacteroids occurs after differentiation, and in the mutant by MtNCR169 gene, undifferentiated bacteria are exposed to lysis [63]. The sequences of NCR peptides genes are extremely variable even within the same species of legumes. The found homologous sequences in different representatives of the IRLC group have a very low percentage of similarity, so the definition of orthologous pairs becomes impossible [64]. Apparently, these plants diverged from a common ancestor, which already had the genes of NCR peptides, a long time ago (Fig.). Subsequently, in the genome of each of them there was duplication of the genes of NCR peptides, which then evolved independently under the influence of a positive (driving) selection [59]. Some genes of different types due to the accumulation of mutations could turn into pseudogenes and be eliminated, so nonorthologic genes began to perform the same biological function. Finally, the similarity of individual sections of sequences of NCR peptides genes indicates the possibility of their variability increase due to illegitimate recombination. The result of the evolution of this gene family was a wide variety of NCR peptides observed in modern representatives of the IRLC group.

According to research of the efficiency of symbiotic nitrogen fixation, bringing bacteroids differentiation to the terminal phase provides the plant (and the symbiotic system as a whole) a significant benefit [65]. Probably, for this 
reason the acquisition in the evolution of the family of NCR peptides genes was a selective advantage of IRLC group plants. In addition, NCR peptides are involved in the background immune response of nodules, the activity of which does not depend on whether there are undesirable (pathogenic) microorganisms in them [63]. The activity in the symbiotic plant organs of the genes of NCR peptides related to the plant immune system and quickly evolving towards diversity, together with the presence of rhizobia systems, which resist the lethal effects of NCR peptides, is a good example of co-evolution of partners in the case of nitrogen-fixing symbiosis.

Thus, to date, in the limited group of legumes, a large gene family has been discovered, which has an organo-specific expression. Its representatives perform a function of a terminal, that is, irreversible differentiation of the symbionts inside the nodule. It is assumed that the genes of NCR peptides arose from related genes of plant defensins in the rapid duplication and diversification of sequences. Many of NCR peptides are interchangeable due to the similarity of the structures, but some acquired new, more specialized functions. The roles, the targets and the modes of action of NCR peptides have been described only for several representatives of this family, and therefore, further research may lead to unexpected and valuable discoveries.

\section{R E F E R E N C E S}

1. Ferguson B.J., Indrasumunar A., Hayashi S., Lin M.H, Li n Y.H., Reid D.E., Gresshoff P.M. Molecular analysis of legume nodule development and autoregulation. Journal of Integrative Plant Biol., 2010, 52(1): 61-76 (doi: 10.1111/j.1744-7909.2010.00899.x).

2. Chen W.-M., Moulin L., Bontemps C., Vandamme P., B ena G., Boivin$\mathrm{M}$ a s s o n C. Legume symbiotic nitrogen fixation by $\beta$-proteobacteria is widespread in nature. J. Bacteriol., 2003, 185(24): 7266-7272 (doi: 10.1128/JB.185.24.7266-7272.2003).

3. M a c Le a n A.M., F i n a n T.M., S a d o w sk y M.J. Genomes of the symbiotic nitrogen-fixing bacteria of legumes. J. Plant Physiol., 2007, 144(2): 615-622 (doi: 10.1104/pp.107.101634).

4. Oldroyd G.E., Downie J.A. Coordinating nodule morphogenesis with rhizobial infection in legumes. Annu. Rev. Plant Biol., 2008, 59: 519-546 (doi: 10.1146/annurev.arplant.59.032607.092839).

5. Old royd G.E. Speak, friend, and enter: signaling systems that promote beneficial symbiotic associations in plant. Nat. Rev. Microbiol., 2013, 11(4): 252-263 (doi: 10.1038/nrmicro2990).

6. Mylo na P., P aw low s k i K., B is se li ng T. Symbiotic nitrogen fixation. The Plant Cell, 1995, 7: 869-885.

7. Mus F., Crook M.B., Garcia K., Garcia Costas A., Geddes B.A., Ko u ri E.D., P a ra masivan P., Ryu M.-H., Oldroyd G.E.D., Poole P.S., Udvardi M.K., V o i g t C.A., A n é J.-M., P e t e r s J.W. Symbiotic nitrogen fixation and the challenges to its extension to nonlegumes. Appl. Environ. Microbiol., 2016, 82(13): 3698-710 (doi: 10.1128/AEM.01055-16).

8. Rolfe B.G., Gress hoff P.M. Genetic analysis of legume nodule initiation. Annu. Rev. Plant Physiol. Plant Mol. Biol., 1988, 39: $297-319$ (doi: 10.1146/annurev.pp.39.060188.001501).

9. Rhizobiaceae: Molekulyarnaya biologiya bakterii, vzaimodeistvuyushchikh s rasteniyami /Pod pedaktsiei G. Spaink; russkii perevod pod redaktsiei I.A. Tikhonovicha, N.A. Provorova [The Rhizobiaceae: molecular biology of model plant-associated bacteria. H.P. Spaink, A. Kondorosi, P. Hooykaas (eds.). Russian translation edited by I.A. Tikhonovich, N.A. Provorov]. St. Petersburg, 2002 (in Russ.).

10. Mergaert P., Uchiumi T., Alunni B., Evanno G., Cheron A., Catrice O., Mausset A.E., Barloy-Hubler F., Galibert F., Kondorosi A., Kondorosi E. Eukaryotic control on bacterial cell cycle and differentiation in the Rhizobiumlegume symbiosis. PNAS USA, 2006, 103(13): 5230-5235 (doi: 10.1073/pnas.0600912103).

11. Van de Velde W., Zehirov G., Szat mari A., Debreczeny M., Ishihara H., Kevei Z., Farkas A., Mikulass K., Nagy A., Tiricz H., Satiat Jeunemaître B., Alunni B., Bourge M., Kucho K., Abe M., Kereszt A., Maroti G., Uchiumi T., Kondorosi E., Mergaert P. Plant peptides govern terminal differentiation of bacteria in symbiosis. Science, 2010, 327(5969): 1122-1126 (doi: 10.1126/science.1184057).

12. S e $n$ D., W e a ve $\mathrm{r}$ R.W. A basis for different rates of N2-fixation by the same strains of $R h i$ zobium in peanut and cowpea root nodules. Plant Sci., 1984, 34(3): 239-246 (doi: 10.1016/S0304-4211(84)80002-4). 
13. Bonaldi K., Gargani D., Prin Y., Fardoux J., Gully D., Nouwen N., Goormachtig S., Giraud E. Nodulation of Aeschynomene afraspera and A. indica by photosynthetic Bradyrhizobium sp. strain ORS285: the nod-dependent versus the nodindependent symbiotic interaction. Mol. Plant-Microbe Interact., 2011, 24(11): 1359-1371 (doi: 10.1094/MPMI-04-11-0093).

14. Mergaert P., Nikovics K., Kelemen Z., Munoury N., Vaubert D., Kondorosi A., Kondorosi E. A novel family in Medicago truncatula consisting of more than 300 nodule-specific genes coding for small, secreted polypeptides with conserved cysteine motifs. Plant Physiol., 2003, 132(1): 161-173 (doi: 10.1104/pp.102.018192).

15. Nallu S., Silverste in, K.A., Zhou P., Young N.D., Vanden Bosch K.A. Patterns of divergence of a large family of nodule cysteine-rich peptides in accessions of Medicago truncatula. The Plant Journal, 2014, 78(4): 697-705 (doi: 10.1111/tpj.12506).

16. Maroti G., Downie J.A., Kondorosi E. Plant cysteine-rich peptides that inhibit pathogen growth and control rhizobial differentiation in legume nodules. Curr. Opin. Plant Biol., 2015, 26: 57-63 (doi: 10.1016/j.pbi.2015.05.031).

17. Shabab M., Arnold M.F., Penterman J., Wommack A.J., Bocker H.T., Price P.A., Griffitts J.S., N ola n E.M., W a lke r G.C. Disulfide cross-linking influences symbiotic activities of nodule peptide NCR247. PNAS USA, 2016, 113(36): 10157-10162 (doi: 10.1073/pnas.1610724113).

18. Fruhling M., Albus, U., Hohnjec N., Geise G., Pühler A., Perlick A.M. A small famiy of broad bean codes for late nodulins containing conserved cysteine clusters. Plant Sci., 2000, 152(1): 67-77 (doi: 10.1016/S0168-9452(99)00219-8).

19. Crockard A., B jourson J., Dazzo B., C o o p e r J.E. A white clover nodulin gene, $d d 23 b$, encoding a cysteine cluster protein, is expressed in roots during the very early stages of interaction with Rhizobium leguminosarum biovar trifolii and after treatment with chitolipooligosaccharide Nod factors. J. Plant Res., 2002, 115(6): 439-447 (doi: 10.1007/s10265-002-0053-7).

20. K a ij a la i n e n S., S c h rod a M., Lindstrom K. Cloning of nodule-specific cDNAs of Galega orientalis. Plant Physiol., 2002, 114(4): 588-593 (doi: 10.1034/j.1399-3054.2002.1140412.x).

21. Scheres B., van Engelen F., van der Knaap E., van de Wiel C., van $\mathrm{K}$ a $\mathrm{m}$ m e n A., B is s e $1 \mathrm{i} \mathrm{ng}$ T. Sequential induction of nodulin gene expression in the developing pea nodule. Plant Cell, 1990, 2(8): 687-700 (doi: 10.1105/tpc.2.8.687).

22. Ka rdailsky I., Yang W-C., Zalensky A., van Kam men A., B isseling T. The pea late nodulin gene PSNOD6 is homologous to the early nodulin genes PSENOD3/14 and is expressed after the leghaemoglobin genes. Plant Mol. Biol., 1993, 23(5): 1029-1037 (doi: 10.1007/BF00021817).

23. Kato T., Kawashima K., Miwa M., Mimura Y., Tamaoki M., Kouchi H., $\mathrm{Sug}$ a n u m a N. Expression of genes encoding late nodulins characterized by a putative signal peptide and conserved cysteine residues is reduced in ineffective pea nodules. Mol. PlantMicrobe Interact., 2002, 15(2): 129-137 (doi: 10.1094/MPMI.2002.15.2.129).

24. S ilverstein K.A., Graham M.A., Paape T.D., Vanden Bos ch K.A. Genome organization of more than 300 defensin-like genes in Arabidopsis. Plant Physiol., 2005, 138(2): 600-610 (doi: 10.1104/pp.105.060079).

25. A erts A.M., Franco is I.E., Ca m mu e B.P., Thevis s e $\mathrm{K}$. The mode of antifungal action of plant, insect and human defensins. Cell. Mol. Life Sci., 2008, 65(13): 2069-2079 (doi: 10.1007/s00018-008-8035-0).

26. V a a ra M., V a a r a T. Polycations as outer membrane-disorganizing agents. Antimicrobial Agents and Chemotherapy, 1983, 24(1): 114-122.

27. B o m a n H.G. Peptide antibiotics and their role in innate immunity. Annu. Rev. Immunol., 1995, 13: 61-92 (doi: 10.1146/annurev.iy.13.040195.000425).

28. Hu a ng H.W. Molecular mechanism of antimicrobial peptides: The origin of cooperativity. $B B A, 2006$, 1758(9): 1292-1302 (doi: 10.1016/j.bbamem.2006.02.001).

29. B r o g d e n K.A. Antimicrobial peptides: Pore formers or metabolic inhibitors in bacteria? Nat. Rev. Microbiol., 2005, 3(3): 238-250 (doi: 10.1038/nrmicro1098).

30. S o chacki K.A., B a rns K.J., B u cki R., We is sha a r C. Real-time attack on single Escherichia coli cells by the human antimicrobial peptide LL-37. PNAS USA, 2011, 108(16): 7781 (doi: 10.1073/pnas.1101130108).

31. Te ix e i r a V., F e i o M.J., B a st o s M. Role of lipids in the interaction of antimicrobial peptides with membranes. Prog. Lipid Res., 2012, 51(2): 149-177 (doi: 10.1016/j.plipres.2011.12.005).

32. Van der We erden N.L., B le a ckley M.R., A nderson M.A. Properties and mechanisms of action of naturally occurring antifungal peptides. Cell. Mol. Life Sci., 2013, 70(19): 3545-3570 (doi: 10.1007/s00018-013-1260-1).

33. E p a nd R.M., V o g e 1 H.J. Diversity of antimicrobial peptides and their mode of action. Biochimica et Biophysica Acta Journal, 1999, 1462(1-2): 11-28.

34. Graha m M.A., S ilve r ste in K.A., C a n no n S.B., Vande n B o s c h K.A. Computational identification and characterization of novel genes from legumes. Plant Physiol., 2004, 135(3): 1179-1197 (doi: 10.1104/pp.104.037531).

35. Silverstein K.A., Graham M.A., Vanden Bosch K.A. Novel paralogous gene 
families with potential function in legume nodules and seeds. Curr. Opin. Plant Biol., 2006, 9(2): 142-146 (doi: 10.1016/j.pbi.2006.01.002).

36. Ganz T. Defensins: antimicrobial peptides of innate immunity. Nat. Rev. Immunol., 2003, 3(9): 710-720 (doi: 10.1038/nri1180).

37. Vriens K., C a m mue B.P., Thevissen K. Antifungal plant defensins: mechanisms of action and production. Molecules, 2014, 19(8): 12280-12303 (doi: 10.3390/molecules190812280).

38. Nagy K., Mikulass K.R., Vegh A.G., Kereszt A., Kondorosi E., Varo G., $\mathrm{Sz}$ e glete $\mathrm{s} \mathrm{Z}$. Interaction of cysteine-rich cationic antimicrobial peptides with intact bacteria and model membranes. Gen. Physiol. Biophys., 2015, 34(2): 135-144 (doi: 10.4149/gpb_2015002).

39. N i c olas P. Multifunctional host defense peptides: Intracellular-targeting antimicrobial peptides. FEBS Journal, 2009, 276(22): 6483-6496 (doi: 10.1111/j.1742-4658.2009.07359.x).

40. Guefrachi I., Nagymihaly M., Pislariu C.I., Van de Velde W., Ratet P., Mars M., Udvardi M.K., Kondorosi E., Mergaert P., Alunni B. Extreme specificity of NCR gene expression in Medicago truncatula. BMC Genomics, 2014, 15(1): 1-16 (doi: 10.1186/1471-2164-15-712).

41. Wang D., Griffitts J., Starker C., Fedorova E., Limpens E., Ivanov S., B isseling T., Lo ng S. A nodule-specific protein secretory pathway required for nitrogenfixing symbiosis. Science, 2010, 327(5969): 1126-1129 (doi: 10.1126/science.1184096).

42. Tiricz H., Szucs A., Farkas A., Pap B., Li ma R.M., Maroti G., Kondorosi E., Ke reszt A. Antimicrobial nodule-specific cysteine-rich peptides induce membrane depolarization-associated changes in the transcriptome of Sinorhizobium meliloti. Appl. Environ. Microbiol., 2013, 79(21): 6737-6746 (doi: 10.1128/AEM.01791-13).

43. Durgo H., Klement E., Hunyadi-Gulyas E., Szucs A., Kereszt A., Medzihradszky K.F., Kondorosi E. Identification of nodule-specific cysteine-rich plant peptides in endosymbiotic bacteria. Proteomics, 2015, 15(13): 2291-2295 (doi: 10.1002/pmic.201400385).

44. H a nd le r A.A., Li m J.E., L o s i c k R. Peptide inhibitor of cytokinesis during sporulation in Bacillus subtilis. Mol. Microbiol., 2008, 68(3): 588-599 (doi: 10.1111/j.1365-2958.2008.06173.x).

45. Penterman J., Abo R.P., D e N is co N.J., Arnold M.F.F., Longhi R., Zan d a M., W a 1 k e r G.C. Host plant peptides elicit a transcriptional response to control the $S i$ norhizobium meliloti cell cycle during symbiosis. PNAS USA, 2014, 111(9): 3561-3566 (doi: 10.1073/pnas.1400450111).

46. Maroti G., Kondorosi E. Nitrogen-fixing Rhizobium-legume symbiosis: are polyploidy and host peptide-governed symbiont differentiation general principles of endosymbiosis? Front. Microbiol., 2014, 5: 1-6 (doi: 10.3389/fmicb.2014.00326).

47. Farkas A., Maroti G., Durgo H., Gyorgypal Z., Lima R.M., Medzihrad s z k y K.F., Ke reszt A., M e rga e rt P., Ko nd orosi E. Medicago truncatula symbiotic peptide NCR247 contributes to bacteroid differentiation through multiple mechanisms. PNAS USA, 2014, 111(14): 5183-5188 (doi: 10.1073/pnas.1404169111).

48. Haag A.F., Baloban M., Sani M., Kerscher B., Pierre O., Farkas A., Longhi R., Boncompagni E., Hérouart D., Dall'Angelo S., Kondorosi E., Zanda M., Mergaert P., Fergus o n G.P. Protection of Sinorhizobium against host cysteine-rich antimicrobial peptides is critical for symbiosis. PLoS Biology, 2011, 9(10): e1001169 (doi: 10.1371/journal.pbio.1001169).

49. Glazebrook J., I chige A., Walke r G.C. A Rhizobium meliloti homolog of the Escherichia coli peptide-antibiotic transport protein SbmA is essential for bacteroid development. Genes and Development, 1993, 7(8): 1485-1497.

50. I c hige A., Walke r G.C. Genetic analysis of the Rhizobium meliloti bacA gene: functional interchangeability with the Escherichia coli sbmA gene and phenotypes of mutants. J. Bacteriol., 1997, 179(1): 209-216.

51. Fergus on G.P., J a n s e n A., M a r low V.L., W a $1 \mathrm{k}$ e r G.C. BacA-mediated bleomycin sensitivity in Sinorhizobium meliloti is independent of the unusual lipid A modification. J. Bacteriol., 2006, 188(8): 3143-3148 (doi: 10.1128/JB.188.8.3143-3148.2006).

52. M a rlow V.L., Ha ag A.F., Kobayashi H., Fletcher V., Scocchi M., Wa lk e r G.C., Fe rgus o n G.P. Essential role for the BacA protein in the uptake of a truncated eukaryotic peptide in Sinorhizobium meliloti. J. Bacteriol., 2009, 191(5): 1519-1527 (doi: 10.1128/JB.01661-08).

53. Karunakaran R., Hag A.F., East A.K., Ramachandran V.K., Pre 11 J., J a m e s E.K., S c o c chi M., Fergus o n G.P., Poole P.S. BacA is essential for bacteroid development in nodules of galegoid, but not phaseoloid, legumes. J. Bacteriol., 2010, 192(11): 2920-2928 (doi: 10.1128/JB.00020-10).

54. We h mei er S., Arnold M.F, M a rlow V.L., Aouida M., Myka K.K., Fletcher V., B e nincasa M., S c o c c hi M., Ramotar D., Fe rgus o n G.P. Internalization of a thiazole-modified peptide in Sinorhizobium meliloti occurs by BacA-dependent and independent mechanisms. Microbiology, 2010, 156: 2702-2713 (doi: 10.1099/mic.0.039909-0). 
55. Crook M.B., Lindsay D.P., Biggs M.B., Bentley J.S., Price J.C., Cle ment S.C., Clement M.J., Long S.R., Griffitts J.S. Rhizobial plasmids that cause impaired symbiotic nitrogen fixation and enhanced host invasion. Mol. Plant-Microbe Interact., 2012, 25(8): 1026-1033 (doi: 10.1094/MPMI-02-12-0052-R).

56. Price P.A., Tanner H.R., Dillon B.A., Shabab M., Walker G.C., Grif fit t s J.S. Rhizobial peptidase HrrP cleaves host-encoded signaling peptides and mediates symbiotic compatibility. PNAS USA, 2015, 112(49): 15244-15249 (doi: 10.1073/pnas.1417797112).

57. Silipo A., Vitiello G., Gully D., Sturiale L., Chaintreuil C., Fardoux J., Gargani D., Lee H.-I., Kulkarni G., Busset N., Marchetti R., Palmigiano A., Moll H., Engel R., Lanzetta R., Paduano L., Parrilli M., Chang W.-S., Holst O., Newman D.K., Garozzo D., D'Errico G., Giraud E., Molinaro A. Covalently linked hopanoid-lipid A improves outer-membrane resistance of a Bradyrhizobium symbiont of legumes. Nat. Commun., 2014, 5: 5106 (doi: 10.1038/ncomms6106).

58. Kulkarni G., Busset N., Molinaro A., Gargani D., Chaintreuil C., Silipo A., Giraud E., New ma n D.K. Specific hopanoid classes differentially affect free-living and symbiotic states of Bradyrhizobium diazoefficiens. MBio Jounal, 2015, 6(5): e01251-15 (doi: 10.1128/mBio.01251-15).

59. Alunni B., Kevei Z., Redondo-Nieto M., Kondorosi A., Mergaert P., Kondorosi E. Genomic organization and evolutionary insights on GRP and NCR genes, two large nodule-specific gene families in Medicago truncatula. Mol. Plant-Microbe Interact., 2007, 20(9): 1138-1148 (doi: 10.1094/MPMI-20-9-1138).

60. Ki m M., Chen Y., Xi J., Wat e rs C., Chen R., Wang D. An antimicrobial peptide essential for bacterial survival in the nitrogen-fixing symbiosis. PNAS USA, 2015, 112(49): 15238-15243 (doi: 10.1073/pnas.1500123112).

61. Horváth B., Domonkos Á., Kereszt A., S z ücs A., Ábrahám E., Ayay din F., B óka K., Chen Y., Chen R., Murray J.D., Udvardi M.K., Kondorosi É., Kal ó P. Loss of the nodule-specific cysteine rich peptide, NCR169, abolishes symbiotic nitrogen fixation in the Medicago truncatula dnf7 mutant. PNAS USA, 2015, 112(49): 15232-15237 (doi: 10.1073/pnas.1500777112).

62. Lang C., Long S.R. Transcriptomic analysis of Sinorhizobium meliloti and Medicago truncatula symbiosis using nitrogen fixation-deficient nodules. Molecular Plant-Microbe Interactions, 2015, 28(8): 856-868 (doi: 10.1094/MPMI-12-14-0407-R).

63. Alu n n i B., Gou ri o n B. Terminal bacteroid differentiation in the legume-rhizobium symbiosis: nodule-specific cysteine-rich peptides and beyond. New Phytologist, 2016, 211(2): 411417 (doi: 10.1111/nph.14025).

64. Kly u k va M.S. Kharakteristika semeistva genov, kodiruyushchikh NCR-peptidy, u gorokha posevnogo (Pisum sativum L.). Magisterskaya dissertatsia [Characterization of gene family encoding NCR peptides in pea (Pisum sativum L.). Magister Thesis]. St. Petersburg, 2016 (in Russ.).

65. O o n o R., D e $\mathrm{n}$ i s o $\mathrm{n}$ R.F. Comparing symbiotic efficiency between swollen versus nonswollen rhizobial bacteroids. Plant Physiol., 2010, 154(3): 1541-1548 (doi: 10.1104/pp.110.163436). 